\title{
Fuel Loading, Fuel Moisture Are Important Components of Prescribed Fire
}

\section{By Russell Stevens}

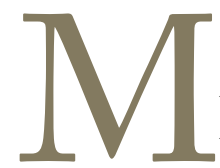

any landowners will be implementing prescribed burns this winter and spring. Prescribed burning is a land management tool that should be used only when needed and after considerable planning, taking into account numerous factors including fireguards, equipment, labor, special concerns, smoke management, and fuel characteristics (loading and moisture).

A common goal with prescribed burning is brush control in pastures. Too often, not enough consideration is given to developing an adequate fuel load and determining fuel moisture for a successful prescribed burn. Without a proper understanding of fuel loading and fuel moisture, a manager risks wasting valuable time and money when attempting to implement a successful prescribed burn.

Grasses are considered 1-hour fuels and are the primary carrier of fire for most prescribed burns in the Great Plains. Fuel loading of grasses is the dry weight of grass in a burn unit, usually expressed in pounds per acre. Like estimating forage production, some experienced managers are able to visually estimate this value with fair accuracy. More accurate estimates can be obtained by clipping, oven-drying, and weighing. A minimum of 1,500 pounds per acre of 1 -hour fuel is usually needed to carry a fire. However, for controlling brush, heavier 1-hour fuel loads are usually needed, depending on brush species and size. For example, 1,500 pounds of 1-hour fuels will probably kill seedling Eastern red cedar (Juniperus virginiana), the only fire-intolerant woody plant encroaching on the eastern and central Great Plains, but not most taller than 2 feet. Fire intensity increases with heavier fuel loads. Fuel loading also affects other fire behavior, such as ignition, rate of spread, and torching (fire racing upward from the ground to treetop).

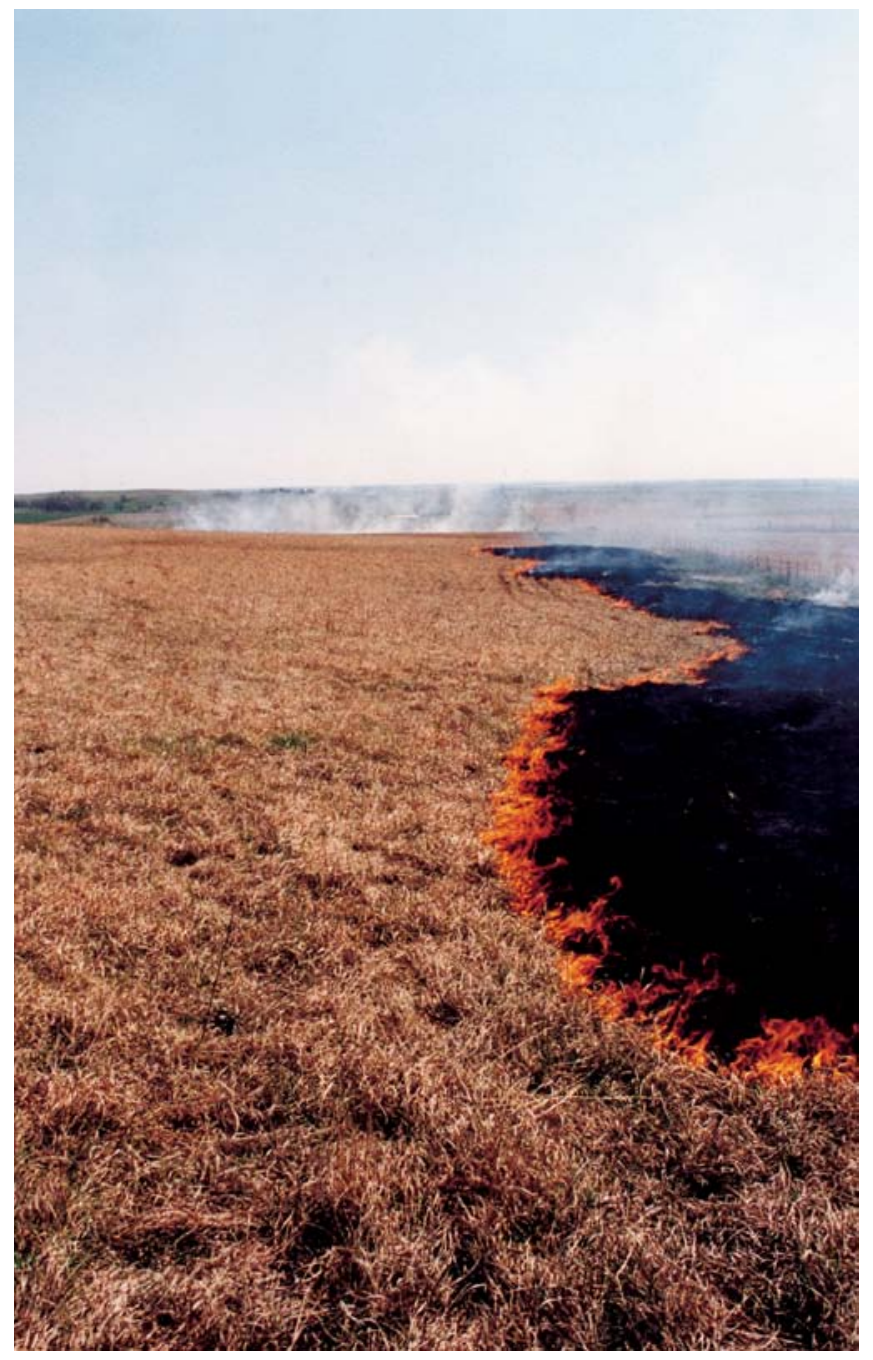




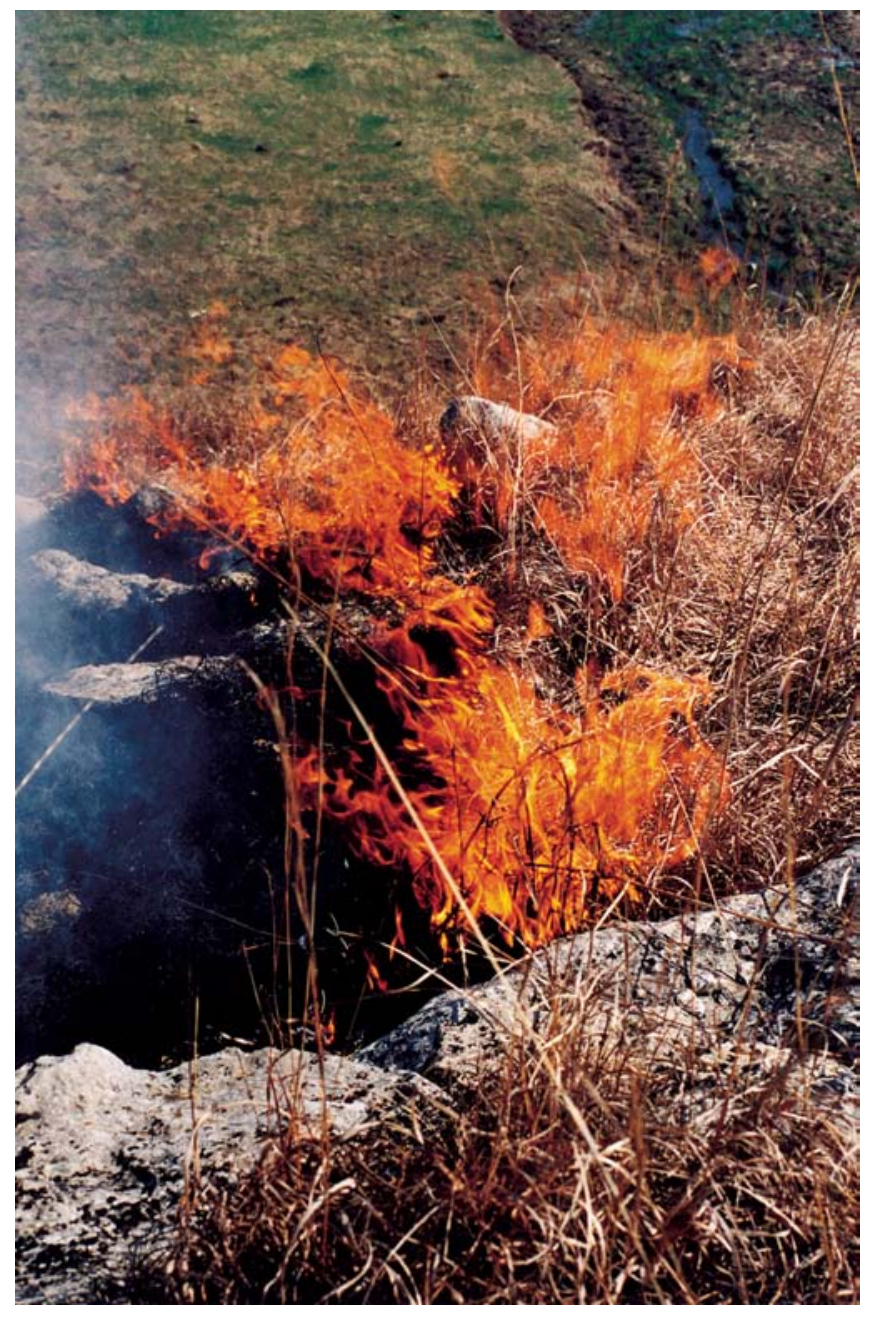

There are 2 kinds of fuel moisture: live and dead. Live fuel moisture is more of an issue when burning live fuel during the growing season or live fuel such as Eastern red cedar during the dormant season. Since most prescribed burns in the Great Plains occur during the dormant season, it is important to know dead fuel moisture for fire control and success. Live fuel moisture can also be important during a dormant season burn. For instance, knowing live fuel moisture of Eastern red cedar will help determine its susceptibility to fire.

Fuels are classified into 4 categories by which they respond to changes in moisture. This response time is referred to as time lag. The 4 categories are the following:

- 1-hour fuels: up to $1 / 4$ inch in diameter

- 10-hour fuels: $1 / 4$ inch to 1 inch in diameter

- 100-hour fuels: 1 inch to 3 inches in diameter

- 1,000-hour fuels: 3 inches to 8 inches in diameter

Examples of 1-hour fuels are grass, leaves, mulch, and litter. Fuel moisture in these fuels can change within 1 hour according to factors such as temperature, rain, humidity, and shade. Conversely, larger diameter fuels, such as deadfalls, brush piles, and so on, take up to 1,000 hours to respond to changes in environmental factors.

Fuel moisture can be determined by clipping and immediately weighing the sample before oven-drying it to a constant weight. Then the following formula can be used to determine percent fuel moisture: [(Wet Weight - Dry Weight $) /$ Dry Weight $] \times 100$. Knowing the moisture in fuels to be burned will help managers understand the susceptibility of fuels for ignition, fire rate of spread, fire intensity and risk of spot fires, torching, and crown fires, all of which are factors that need to be managed to control the fire as well as to achieve desired goals.

Managers who understand and properly apply their knowledge of fuel loading and fuel moisture will have greater success in achieving their goals for using prescribed fire.

The Samuel Roberts Noble Foundation (www.noble.org), headquartered in Ardmore, Oklahoma, is a nonprofit organization conducting agricultural, forage improvement, and plant biology research; providing grants to nonprofit charitable, educational, and health organizations; and assisting farmers and ranchers through educational and consultative agricultural programs. 